\title{
CUANTIFICACION DEL TRANSPORTE DE AGUA COSTA-OCEANO A TRAVES DE FILAMENTOS Y REMOLINOS RICOS EN CLOROFILA $a$, EN LA ZONA CENTRO-SUR DE CHILE (35.5-37.5 $\mathrm{S})$
}

\section{CUANTIFICATION OF COAST-OCEAN WATER TRANSPORT THROUGH FILAMENTS AND EDDIES WITH HIGH CHLOROPHYLL a CONTENT, IN CENTRAL-SOUTH CHILE (35.5-37.5 ${ }^{\circ}$ )}

\author{
Carolina Grob, Renato A. Quiñones \& Dante Figueroa \\ Departamento de Oceanografía, Facultad de Ciencias Naturales y Oceanográficas, Universidad de Concepción, \\ Casilla 160-C, Concepción. E-mail: mgrob@profc.udec.cl
}

\begin{abstract}
RESUMEN
Se cuantificó el transporte neto de agua superficial entre la zona costera y zona oceánica a través de estructuras de mesoescala (filamentos y remolinos) identificadas a partir de imágenes satelitales diarias de clorofila $a$ (SeaWIFS). El transporte se cuantificó en el sector comprendido entre los 35.5 y $37.5^{\circ} \mathrm{S}$ de la zona centro-sur de Chile, para un período de 15 días en octubre de 1998 y otro de igual duración en julio de 1999, correspondientes a los cruceros MIRC I y MIRC II. En ambos cruceros el transporte neto de agua tuvo lugar desde la zona costera hacia la zona oceánica, con $6.22 \times 10^{4} \mathrm{~m}^{3} \mathrm{~s}^{-1}$ para el período del MIRC I y de $1.64 \times 10^{4} \mathrm{~m}^{3} \mathrm{~s}^{-1}$ para el MIRC II. El sector centro-sur de Chile estudiado es un exportador neto de agua a través de filamentos y remolinos.
\end{abstract}

Palabras Claves: Surgencia, filamentos, remolinos, Sistema de la Corriente de Humboldt, Chile.

\section{ABSTRACT}

The net transport of surface water, between the coastal and oceanic zone, through mesoscale structures such as filaments and eddies was quantified in central-south Chile $\left(35.5\right.$ to $\left.37.5^{\circ} \mathrm{S}\right)$. This transport was quantified by identifying filaments and eddies on daily chlorophyll $a$ images (SeaWIFS) for two 15 days periods taking place in October 1998 and in July 1999. These periods correspond to the MIRC I and MIRC II cruises respectively. In both cruises the estimated superficial transport showed a net flow from the coastal to the oceanic zone, of $6.22 \times 10^{4} \mathrm{~m}^{3} \mathrm{~s}^{-1}$ and 1.64 $\mathrm{x} 10^{4} \mathrm{~m}^{3} \mathrm{~s}^{-1}$ during MIRC I and MIRC II, respectively. The central-south part of Chile is a net exporter of water through filaments and eddies.

KeYwords: Upwelling, filaments, eddies, Humboldt Current System, Chile .

\section{INTRODUCCION}

El uso de imágenes satelitales que representan características superficiales del agua de mar (temperatura y concentración de clorofila $a$, por ejemplo) ha permitido estudiar procesos que ocurren a escalas espaciales y temporales imposibles de abarcar mediante cruceros oceanográficos. Si bien éstos últimos tienen la ventaja de poder hacer mediciones en toda la columna de agua, no permiten tener una visión de meso $(1 \mathrm{a} 1.000 \mathrm{~km})$ o macroescala (más de $1.000 \mathrm{~km}$ ) en tiempo real de 
los procesos físicos y biológicos que están ocurriendo. Una combinación de datos satelitales e "in situ" pareciera ser una mejor alternativa para estudiar procesos de mayor escala en el océano.

Los flujos a mesoescala cumplen un importante rol en la exportación e importación de aguas entre sectores altamente productivos y sectores más bien oligotróficos del océano mundial. En este contexto, Huthnance (1995) describió en detalle diversos procesos físicos que favorecen o impiden el transporte de material entre la plataforma continental y el océano abierto, destacando los balances geostrófico (flujo a lo largo de la costa) y ageostrófico, ambos en estrecha relación con la batimetría.

Es precisamente cuando se relaja o inhibe el flujo geostrófico cuando se generan los mayores intercambios entre la zona costera y la zona oceánica, especialmente a través del transporte de Ekman durante la surgencia costera y a través de estructuras de mesoescala tales como filamentos y eddies o remolinos que se desprenden de estos filamentos. Ambas estructuras son generadas ageostróficamente a partir de inestabilidades en los frentes de surgencia, en combinación con la dinámica y topografía de la región (Huthnance 1995).

Filamentos y remolinos formados en sistemas de borde oriental se caracterizan, en general, por presentar a nivel superficial aguas de baja temperatura y alta salinidad, alta densidad y una alta concentración de nitratos y clorofila a (Brink 1987; Kosro et al. 1991), salvo algunas excepciones en que el agua que aflora es demasiado somera, como se ha visto en el norte de Chile (Sobarzo \& Figueroa 2001). Dado que pueden alcanzar hasta $300 \mathrm{~km}$ costa-afuera y entre 100 y 200 m en profundidad (Brink 1987; Hill et al. 1998), los filamentos son potencialmente importantes en la exportación de material hacia el océano abierto en sistemas de borde oriental tales como los de California, Chile y Sudáfrica (Hill et al. 1998).

En este trabajo se cuantifica el transporte superficial de aguas, a través de filamentos y remolinos, entre la zona costera y zona oceánica del sector centro-sur de Chile ubicado entre los 35.5 y $37.5^{\circ} \mathrm{S}$ (Figura 1). Para ello se consideró un período de 15 días en octubre de 1998 y otro de igual duración en julio de 1999, correspondientes a los cruceros oceanográficos MIRC I y MIRC II respectivamente (Programa FONDAP-Humboldt).

El área de estudio presenta altos niveles de productividad primaria (Daneri et al. 2000) y desembarques pesqueros (Sernapesca, 2000), lo que induce a hipotetizar que la zona oceánica es fuertemente subsidiada en material biológico por la zona costera, a través de los filamentos y remolinos descritos.

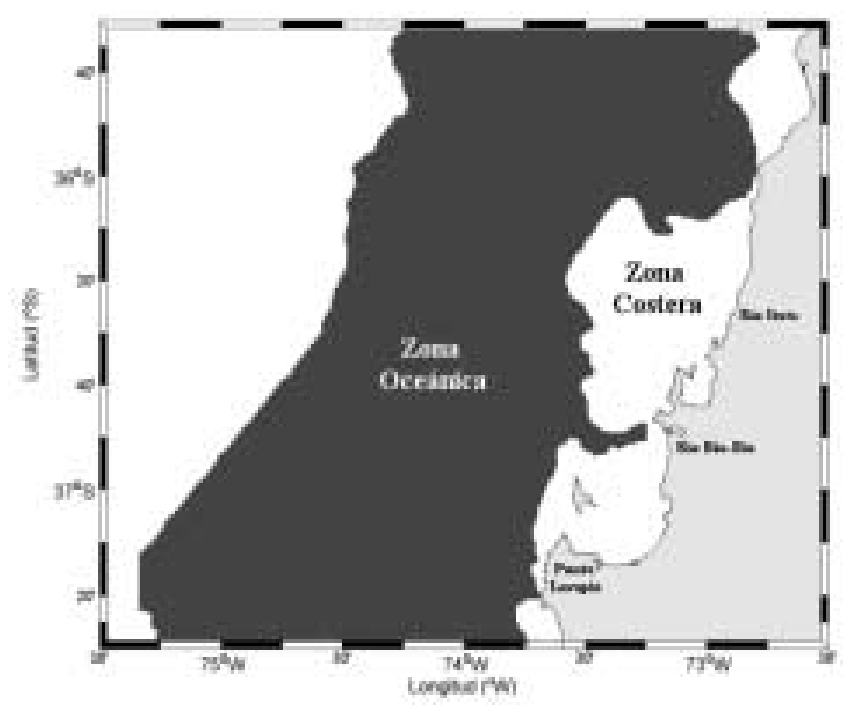

FIGURA 1. Area de estudio y límites operacionales establecidos entre zona costera y oceánica.

FIGURE 1. Study area and optional limits established between the coastal and the oceanic zone. 


\section{ANTECEDENTES DEL AREA DE ESTUDIO}

El área de estudio se encuentra ubicada frente al litoral centro-sur de Chile, entre los 35.5 y $37.5^{\circ}$ de latitud sur y 72.5 a $75.5^{\circ}$ de longitud oeste (Figura 1). Los patrones de circulación geostrófica descritos para la plataforma continental frente a Talcahuano indican un flujo en superficie hacia el ecuador y subsuperficial hacia el polo durante períodos de surgencia activa. Con vientos del norte se origina una corriente más lenta hacia el polo en casi toda la columna de agua (Ahumada 1989) con tendencia a seguir la batimetría (Sobarzo 1994). En el área de estudio se encuentran presentes durante todo el año las siguientes masas de agua (1) Agua Subantártica (ASA, asociada a la corriente de Humboldt), con salinidad menor a 34.3 , temperatura mayor a $12^{\circ} \mathrm{C}$ y concentración de oxígeno mayor a $6.5 \mathrm{ml} / \mathrm{L}$, en los primeros 100 a $150 \mathrm{~m}$, (2) Agua Ecuatorial Subsuperficial (AESS), con salinidad mayor a 34.5 , temperatura entre 9 y $12^{\circ}$ C y concentración de oxígeno menor a $1 \mathrm{ml} / \mathrm{L}$, ubicada entre los 100 y $380 \mathrm{~m}$ y concentraciones de nutrientes más altas que las otras masas de agua identificadas, y (3) Agua Intermedia de la Antártica (AIA), con salinidad entre 34.35 y 34.5 , temperatura entre 4 y $8^{\circ} \mathrm{C}$ y concentración de oxígeno entre 2 y $5 \mathrm{ml} / \mathrm{L}$, entre los 400 y $1.000 \mathrm{~m}$ de profundidad (Sobarzo 1994).

Entre septiembre y marzo, época en que predominan los vientos del sur y suroeste (Saavedra,1980), se observan varios focos de surgencia (Cáceres 1992), cuyos frentes se encuentran por lo general asociados al quiebre de la plataforma continental (Cáceres \& Arcos 1991; Cáceres 1992). Dos importantes cañones submarinos, el del río Bío-Bío (36 52 'S) y el del río Itata $\left(36^{\circ} 05^{\prime} \mathrm{S}\right)$, que enmarcan el sector más ancho de la plataforma continental frente a las costas de Chile (Terraza del Itata), provocan flujos ageostróficos que facilitan el intercambio plataforma-océano (Sobarzo 1999). El cañón del Bío-Bío, por ejemplo, puede actuar como una pared, aumentando el transporte mar afuera (Sobarzo et al. 2001). Para este sector se ha descrito una surgencia costera muy particular, con transporte de agua mar afuera en los niveles superior e inferior y una corriente de retorno en el nivel medio, producto de la particular topografía submarina (Sobarzo 1999). En el área de estudio se ha visto, además, una alta ocurrencia de estructuras de mesoescala, con filamentos que alcanzan los $200 \mathrm{~km}$ costaafuera, remolinos anticiclónicos de hasta $50 \mathrm{~km}$ de diámetro frente a la Terraza del Itata y ciclónicos de menor diámetro frente a Punta Lavapié (Djurfeldt 1989; Cáceres 1990; Cáceres \& Arcos 1991; Cáceres 1992; Thomas 1999), que estarían naciendo aproximadamente en el borde de la plataforma continental (Cáceres 1992). Para los mismos períodos que se analizarán en este trabajo, González et al. (en preparación), muestran que la forma descrita por los filamentos observados en imágenes satelitales coincide con los flujos que produce el balance geostrófico.

Entre mayo y julio, cuando los vientos predominantes son del cuadrante norte (Saavedra 1980), se produce un flujo hacia la costa y cierta homogeneización de la columna de agua (Strub et al. 1998), contrarrestada por el aumento de la estratificación inducido por la entrada de agua dulce desde los ríos Bío-Bío e Itata. Estos dos ríos tienen una fuerte influencia sobre la circulación y características hidrográficas superficiales en la costa en esa época del año.

Las características del área de estudio aquí mencionadas hacen a este sector de Chile particularmente interesante para evaluar cuantitativamente el intercambio superficial de agua entre la zona costera y la zona oceánica a través de estructuras de mesoescala, especialmente en época de surgencias.

\section{MATERIALES Y METODOS}

\section{DEFINICIÓN DE ESCALAS ESPACIO-TEMPORALES}

Se definió el quiebre de la plataforma continental (representado por la isóbata de los $200 \mathrm{~m}$ ) como límite entre la zona costera y la zona oceánica adyacente, dado que los procesos que ocurren sobre la plataforma presentan características y escalas similares entre sí y distintas a la zona ubicada por fuera del quiebre (Pickard \& Emery 2000). Como límite externo para el estudio se definió una distancia arbitraria de $185 \mathrm{~km}$ desde la costa, escogida en base a la distancia promedio que alcanzan los filamentos observados dentro del área de estudio en trabajos anteriores (Cáceres 1990; Cáceres 1992; Thomas 1999) (Figura 1). Para definir la profundi- 
dad (límite vertical) que alcanzan los filamentos identificados dentro del área de estudio (35.5 a $\left.37.5^{\circ} \mathrm{S}\right)$, se compararon perfiles de temperatura y salinidad tomados dentro y fuera de una de estas estructuras (Figuras $2 \mathrm{~B}, 2 \mathrm{C}, 3 \mathrm{~B}$ y $3 \mathrm{C}$ ), teniendo en consideración que la profundidad promedio observada en otras re-

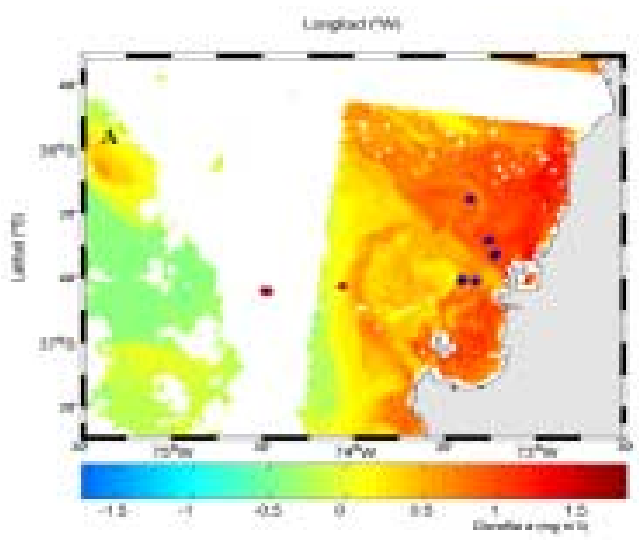

giones del mundo es de entre 100 y 200m (Brink 1987; Hill et al. 1998). Los perfiles utilizados se obtuvieron durante los cruceros MIRC I (15 al 30 de octubre de 1998) y MIRC II (3 al 17 de julio de 1999), por lo que los períodos de estudio quedaron acotados a las fechas en que se realizaron estas dos campañas oceanográficas.

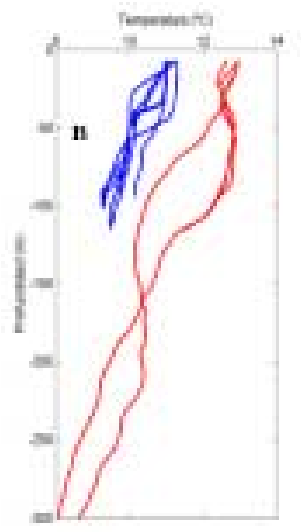

Figura 2. A) Imagen satelital de clorofila $a$ para el día 17 de Octubre de 1998 (período MIRC I). En azul y rojo se indican las estaciones que se encontraron dentro y fuera del filamento identificado para ese día, respectivamente. B) Perfiles de temperatura tomados en las estaciones dentro (azul) y fuera (rojo) del filamento. C) Perfiles de salinidad tomados en las estaciones dentro (azul) y fuera (rojo) del filamento.

Figure 2. A) Satellite image of chlorophyll a, October 17th, 1998 (MIRC I period). Blue and red dots indicate stations found inside and outside of a filament identified for that day, respectively. B) Temperature profiles taken inside (blue) and outside (red) of the filament. C) Salinity profiles taken inside (blue) and outside (red) of the filament.
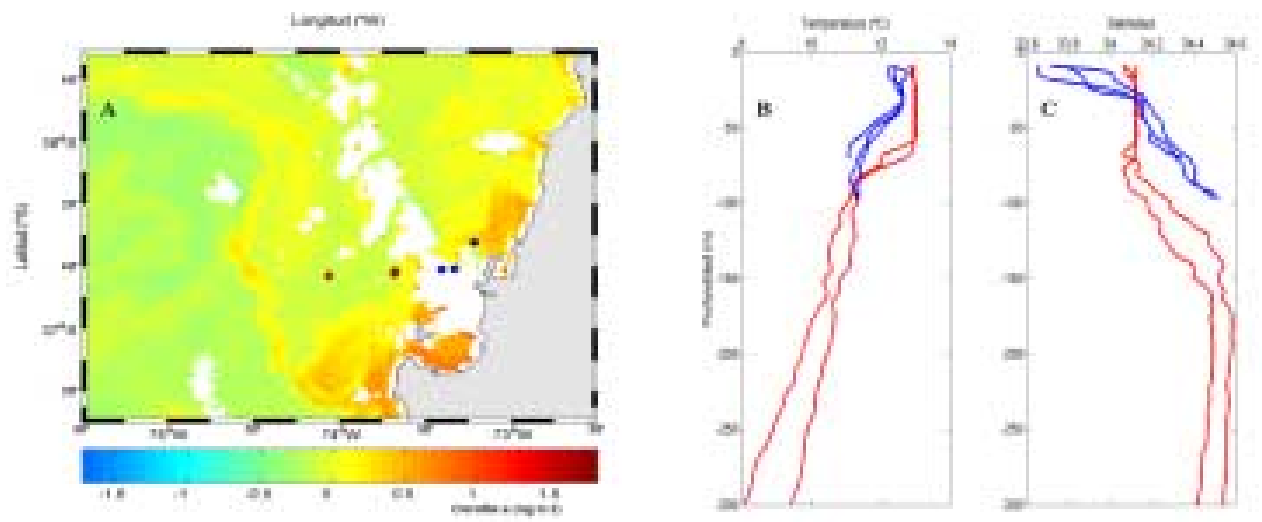

FigurA 3. A) Imagen satelital de clorofila $a$ para el día 15 de Julio de 1999 (período MIRC II). En azul y rojo se indican las estaciones que se encontraron dentro y fuera del filamento identificado para ese día, respectivamente. B) Perfiles de temperatura tomados en las estaciones dentro (azul) y fuera (rojo) del filamento. C) Perfiles de salinidad tomados en las estaciones dentro (azul) y fuera (rojo) del filamento.

FIGURE 3. A) Satellite image of chlorophyll $a$, July 15th, 1999 (MIRC II period). Blue and red dots indicate stations found inside and outside of a filament identified for that day, respectively. B) Temperature profiles taken inside (blue) and outside (red) of the filament. C) Salinity profiles taken inside (blue) and outside (red) of the filament. 
Cuantificacion del transporte costa-océano en la zona centro-sur de Chile. GROB, C. ET AL.

\section{CAlculo de transportes}

\section{TRANSPORTE DE EKMAN}

El transporte teórico de Ekman (e.g. Pond \& Pickard 1997) se calculó como una referencia al transporte que se estaría produciendo por efecto del viento en el sector específico de la costa donde se obtuvieron los datos para calcularlo. Este transporte se calculó sólo para el crucero MIRC I, a partir de registros de velocidad del viento obtenidos cada 10 minutos en una estación meteorológica ubicada en Punta Lavapié (37 $\left.10^{\prime} \mathrm{S} ; 7^{\circ} 35^{\prime} \mathrm{W}\right)$. El promedio vectorial diario del viento se descompuso en sus componentes ortogonales para calcular el esfuerzo $\tau_{m}\left(\mathrm{~N} \mathrm{~m}^{-2}\right)$, paralelo a la costa (dirección norte-sur) sobre la superficie del océano $\eta$ (1).

$\tau_{m}=\mathrm{C}_{\mathrm{d}} \rho_{\mathrm{a}} \mathrm{W}_{\mathrm{v}}|\mathrm{W}|$

donde $\mathrm{C}_{\mathrm{d}}$ es el coeficiente adimensional de arrastre, aquí considerado como constante e igual a 0.0013 , $\mathrm{g}_{\mathrm{a}}$ es la densidad del aire $\left(1.22 \mathrm{~kg} \mathrm{~m}^{-3}\right), \mathrm{W}_{\mathrm{v}}$ es la componente paralela a la costa (dirección norte-sur) de la velocidad del viento, $\mathrm{W}$ es la magnitud del viento $\left(\mathrm{m} \mathrm{s}^{-1}\right)$. Luego se calculó el transporte de masa $\mathrm{Q}_{\mathrm{x}}\left(\mathrm{m}^{2} \mathrm{~s}^{-1}\right)$, por $1 \mathrm{~m}$ y perpendicular a la costa $(2)$.

$\mathrm{Q}_{\mathrm{x}}=\tau_{m} / \rho f$

donde $f$ es el parámetro de Coriolis y $\rho$ es una densidad representativa del agua de mar $\left(1027 \mathrm{~kg} \mathrm{~m}^{-}\right.$ ${ }^{3}$ ). El Indice de Surgencia I, o transporte teórico de Ekman, corresponde a la estandarización de $\mathrm{Q}_{\mathrm{x}}$ a $100 \mathrm{~m}$ de costa (Bakun 1975) (3).

$I_{s}=Q_{x} \times 100$

Por falta de registros de viento en Punta Lavapié para Julio de 1999, para el crucero MIRC II sólo se hará referencia al comportamiento de los viento tomados a las 14:00hrs en la estación meteorológica de Bellavista $\left(36.78^{\circ} \mathrm{S} ; 73.12^{\circ} \mathrm{W}\right)$, mostrados por González et al. (en preparación).

Con los $I_{s}$ calculados se identificaron eventos de surgencia ( $\mathrm{I}_{\mathrm{s}}$ superior a $0.4 \times 10^{3} \mathrm{~m}^{3} \mathrm{~s}^{-1}$ aproximadamente según Arcos, 1987), períodos de relajación y períodos de subsidencia (I negativos).
TRANSPORTE POR ESTRUCTURAS DE MESOESCALA (FILAMENTOS Y REMOLINOS)

1. ANÁLISIS DE IMÁGENES DE CLOROFILA A (SEAWIFS). El cálculo de transporte por estructuras de mesoescala (filamentos y remolinos) se basó en el concepto de "satellite feature tracking", que consiste en identificar un patrón o característica particular en imágenes satelitales, ya sea de temperatura o de color del mar, y observar el cambio de posición que experimenta esa característica de un día a otro, es decir, su desplazamiento para obtener vectores de velocidad de corrientes superficiales (Breaker et al. 1994). Este concepto supone que ambos parámetros (temperatura y concentración superficial de clorofila $a$ ) sirven como trazadores pasivos con características conservativas y asume, además, un movimiento puramente advectivo de las estructuras definidas para el estudio de corrientes superficiales (Breaker et al. 1994). Si bien la temperatura y concentración superficial de clorofila $a$ pueden variar por procesos físicos y biológicos respectivamente, se estima que la escala temporal típica de los filamentos es de 10 a 60 días (Hill et al. 1998) y que por las características de frente que presentan los bordes de los filamentos, la advección fuera de éstos no debiera ser importante (Shillington et al.1990). Smyth et al. (2001), por su parte, observaron características relativamente homogéneas de temperatura y distribución de clorofila $a$ dentro de un filamento estudiado en la costa ibérica por un período de 10 días. Para el mismo período estos autores encontraron, además, una diferencia de tan sólo $3 \mathrm{~cm} \mathrm{~s}^{-1}$ entre velocidades medidas con ADCP a $25 \mathrm{~m}$ de profundidad y velocidades calculadas a partir de imágenes de TSM.

Considerando todo lo anterior, se asumió un comportamiento homogéneo y conservativo de las variables físicas y biológicas de los filamentos y remolinos observados en imágenes satelitales SeaWiFS sucesivas para el período de 15 días que duró cada uno de los cruceros MIRC.

En imágenes diarias de clorofila $a$, de resolución $1.1 \mathrm{~km}$ x $1.1 \mathrm{~km}$ (15 imágenes para el período correspondiente al MIRC I y 11 para el MIRC II) se definió como estructuras de mesoescala todas aquellas que presentaran una concentración superficial mayor a $2.5 \mathrm{mg} \mathrm{m}^{-3}$. Se determinó el área ocupada diariamente por estas estructuras en la zona oceánica, considerando el aumento o la disminu- 
ción de ésta como desplazamiento de filamentos y remolinos desde la zona costera hacia la zona oceánica o en sentido contrario, respectivamente, debido a un movimiento puramente advectivo (y no a fenómenos locales o a advección desde la misma zona oceánica) como lo establecen Breaker et al. (1994). Para los días con cobertura nubosa total esta área se determinó promediando los días previo y posterior, y para los días con cobertura parcial se determinó observando la tendencia de los días mencionados. El volumen diario transportado a través del quiebre de la plataforma continental se calculó finalmente como el área ocupada por las estructuras en la zona oceánica un día, menos el área ocupada por éstas el día anterior, multiplicada por la profundidad que alcanzaban las estructuras en cada crucero, es decir, multiplicada por $100 \mathrm{~m}$ $(0.1 \mathrm{~km})$. Este resultado, en $\mathrm{km}^{3}$ día $^{-1}$, se multiplicó por 11574.074 para convertirlo a $\mathrm{m}^{3} \mathrm{~s}^{-1}$. El transporte neto a través del quiebre de la plataforma continental para cada crucero se calculó como prome- dio de los transportes diarios calculados.

2. ANALISIS DE IMÁGENES DE TSM. En imágenes satelitales NOAA de Temperatura Superficial del Mar (TSM) del 20, 22 al 23 y 26 al 30 de Octubre de 1998 (MIRC I) se identificó la banda de temperatura entre los 10 y $\operatorname{los} 11^{\circ} \mathrm{C}$, característica de las aguas de surgencia para la región, y se analizó su desplazamiento en sentido este-oeste. Se calculó la diferencia de área ocupada por esta banda de temperatura entre días consecutivos utilizando la función "Measurement explorer" de la sección de calibración de imágenes del programa OPTIMAS 6.1. Esta función permite dibujar manualmente los contornos de la banda de temperatura seleccionada, para que el programa calcule automáticamente el área. El volumen transportado se calculó de igual forma que para las imágenes de clorofila $a$, de forma de poder comparar ambos resultados. Por falta de imágenes de TSM no fue posible realizar el mismo análisis para el MIRC II.

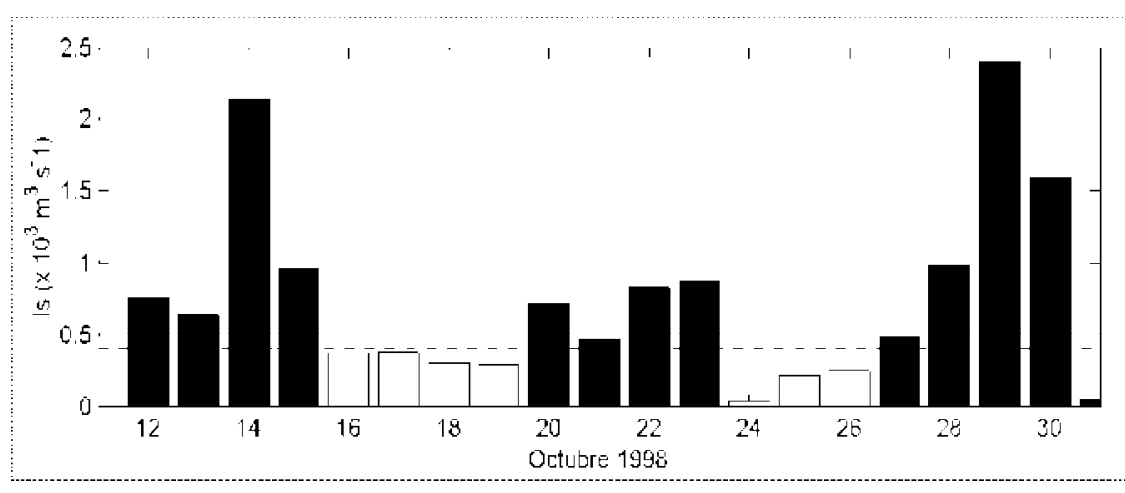

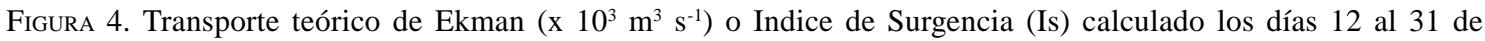
Octubre de 1998 (período MIRC I) para el sector de Punta Lavapié (37010' S; 73³5' W). Se indican períodos de surgencia fuerte (barras negras), surgencia débil (barras grises) y relajación (barras blancas), además del límite de $0.4 \times 10^{3} \mathrm{~m}^{3} \mathrm{~s}^{-1}$ (línea segmentada) que los identifica.

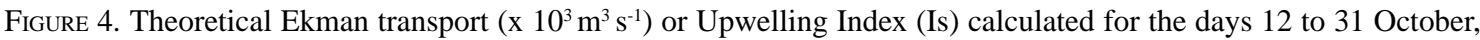

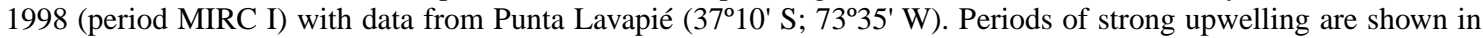
black, weak upwelling in gray y relaxation periods in white. The dashed line shows the limit of $0.4 \times 10^{3} \mathrm{~m}^{3} \mathrm{~s}^{-1}$ that differentiates them.

\section{RESULTADOS}

TRANSPORTE DE EKMAN

Los I calculados para el crucero MIRC I con datos de Punta Lavapié (similares a los encontrados en época de surgencia por Arcos \& Navarro 1986) in- dican 3 eventos de surgencia, 2 relativamente intensos (12 al 15 y 27 al 31), con transportes máximos de $2.14 \times 10^{3}$ y $2.41 \times 10^{3} \mathrm{~m}^{3} \mathrm{~s}^{-1}$ respectivamente, $\mathrm{y}$ uno leve (20 al 23), con un máximo de $0.88 \times 10^{3}$ $\mathrm{m}^{3} \mathrm{~s}^{-1}$ (Figura 4). Entre estos eventos de surgencia se detectaron períodos de relajación de 3 y 4 días. 
TRANSPORTE POR ESTRUCTURAS DE MESOESCALA (FILAMENTOS Y REMOLINOS)

1.- ANÁLISIS DE IMÁGENES DE CLOROFILA $a$ (SeaWIFS). Durante el primer crucero se observaron filamentos de entre 30 y $50 \mathrm{~km}$ de ancho, que por lo general alcanzaban una distancia mayor a $185 \mathrm{~km}$ desde la costa (límite oeste de la zona de estudio), y la formación de algunos remolinos ciclónicos cerca de Punta Lavapié (Figura 2A). Considerando una profundidad máxima de $100 \mathrm{~m}$ para las estructuras de mesoescala, se calcularon transportes diarios de entre $1.50 \times 10^{6}$ y $5.49 \times 10^{6} \mathrm{~m}^{3} \mathrm{~s}^{-1}$ hacia la zona oceánica y de hasta $7.90 \times 10^{6} \mathrm{~m}^{3} \mathrm{~s}^{-1}$ en sentido contrario (Figura 5A, Tabla I), resultando en un transporte neto de agua (promedio para todo este período de estudio) de $6.22 \times 10^{4} \mathrm{~m}^{3} \mathrm{~s}^{-1}$ hacia la zona oceánica.
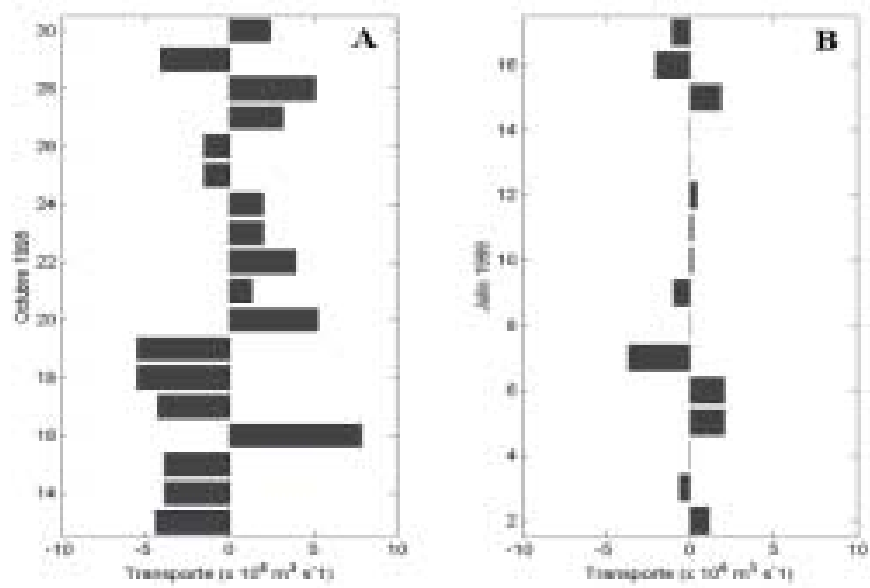

Figura 5. Transporte diario de agua a través de filamentos y remolinos (estructuras de mesoescala), desde la zona costera hacia la zona oceánica (representado por valores negativos) y en sentido contrario (representado por valores positivos). A) Transporte calculado a partir de imágenes de clorofila $a$ para el período MIRC I. B) Transporte calculado a partir de imágenes de clorofila $a$ para el período MIRC II.

FiguRE 5. Daily water transport through filaments and eddies (mesoscale features), from the coastal to the oceanic zone (represented by negative values) and in the opposite direction (represented by positive values). A) Transport calculated using chlorophyll a images for the MIRC I period. B) Transport calculated using chlorophyll $a$ images for the MIRC II period.

Durante el crucero MIRC II los filamentos presentaron extensiones muy inferiores (máximo $90 \mathrm{~km}, 35 \mathrm{~km}$ de ancho) a los observados durante el MIRC I, sin que se detectara la formación de ningún remolino (Figura 3A). Las más altas concentraciones de clorofila $a$ se observaron cerca de la costa, aumentando su extensión costa-afuera de norte a sur, para alcanzar las máximas extensiones en los alrededores del Golfo de Arauco y la Bahía de Concepción. Si bien en 10 de 16 días el transporte superficial de agua calculado resultó, desde la zona oceánica hacia la zona costera, con valores entre $2.08 \times 10^{6}$ y $0.02 \times 10^{6} \mathrm{~m}^{3} \mathrm{~s}^{-1}$ (Figura 5B, Tabla I), durante 5 de los 6 días restantes el transporte en sentido contrario fue tan importante, que el transporte neto para el período en cuestión fue de $1.64 \times 10^{4} \mathrm{~m}^{3} \mathrm{~s}^{-1}$ desde la zona costera hacia la zona oceánica.

El día 17 de octubre de 1998 (crucero MIRC I) se llevó a cabo un total de 12 estaciones oceanográficas dentro del área de estudio, 7 de las cuales se encontraban dentro de un filamento y 4 fuera de éste, según lo observado en días anteriores y posteriores (Figura 2A). En los perfiles de temperatura y salinidad se observan claramente las diferencias entre estos 2 grupos de estaciones, presentando las aguas del filamento una menor temperatura y una mayor salinidad que las aguas fuera de éste. Mientras la temperatura encontrada dentro de los filamentos indica la presencia de AESS (Figura 2B), la salinidad presenta más bien características de ASA (Figura 2C). 
Gayana 67(1), 2003

TABLA I: Transporte diario estimado a través de estructuras de mesoescala (filamentos y remolinos) desde la zona costera hacia la zona oceánica (representado por valores negativos) y en sentido contrario (representado por valores positivos), para ambos cruceros.

TABLE I: Daily transport estimated through mesoscale structures (filaments and eddies) from the coast to the ocean (negative values) and from the ocean to the coast (positive values), for both cruises.

\begin{tabular}{|c|c|c|c|c|}
\hline \multicolumn{3}{|c|}{ MIRC I } & \multicolumn{2}{|r|}{ MIRC II } \\
\hline $\begin{array}{l}\text { D as de } \\
\text { Octubre, } \\
1998\end{array}$ & $\begin{array}{c}\text { Transporte }\left(\mathrm{x} 10^{6} \mathrm{~m}^{3} \mathrm{~s}^{-1}\right) \\
\text { estimado a partir de } \\
\text { imágenes de clorofila a }\end{array}$ & $\begin{array}{c}\text { Transporte }\left(\mathrm{x} 10^{6} \mathrm{~m}^{3} \mathrm{~s}^{-1}\right) \\
\text { estimado a partir de } \\
\text { imágenes de TSM }\end{array}$ & $\begin{array}{l}\text { D as de } \\
\text { Julio, } \\
1999\end{array}$ & $\begin{array}{c}\text { Transporte }\left(\mathrm{x} 10^{6} \mathrm{~m}^{3} \mathrm{~s}^{-1}\right) \\
\text { estimado a partir de } \\
\text { imágenes de clorofila a }\end{array}$ \\
\hline 13 & -4.44 & - & 02 & 1.12 \\
\hline 14 & -3.85 & - & 03 & -0.60 \\
\hline 15 & -3.85 & - & 04 & 0.05 \\
\hline 16 & 7.90 & - & 05 & 2.08 \\
\hline 17 & -4.24 & - & 06 & 2.08 \\
\hline 18 & -5.49 & - & 07 & -3.66 \\
\hline 19 & -5.49 & - & 08 & 0 \\
\hline 20 & 5.26 & 0.27 & 09 & -0.96 \\
\hline 21 & 1.37 & 0.27 & 10 & 0.18 \\
\hline 22 & 3.93 & 2.85 & 11 & 0.18 \\
\hline 23 & 1.99 & - & 12 & 0.44 \\
\hline 24 & 1.99 & - & 13 & 0.02 \\
\hline 25 & -1.50 & - & 14 & 0.02 \\
\hline 26 & -1.50 & -2.9 & 15 & 1.84 \\
\hline 27 & 3.23 & -1.95 & 16 & -2.01 \\
\hline 28 & 5.13 & -7.166 & 17 & -1.05 \\
\hline 29 & -4.07 & -7.166 & - & - \\
\hline 30 & 2.49 & - & - & - \\
\hline
\end{tabular}

El día 15 de julio fue posible identificar 3 perfiles dentro y 3 perfiles fuera de un pequeño filamento que se estaba formando cerca de la costa (Figura 3A). Al igual que para el primer período analizado (MIRC I) se encontraron claras diferencias de temperatura y salinidad hasta alrededor de los $100 \mathrm{~m}$. Mientras que la temperatura dentro del filamento resultó ser levemente menor que fuera de éste hasta la profundidad señalada (Figura 3B), la salinidad mostró esta tendencia sólo hasta alrededor de los $25 \mathrm{~m}$ (Figura 3C). Bajo los $25 \mathrm{~m}$, la salinidad fue mayor dentro de la estructura que fuera de ésta, por lo tanto, la influencia de aguas continentales sería sólo hasta esa profundidad.

2.- ANALISIS DE IMÁGENES DE TSM. Al graficar la banda de temperatura seleccionada para el crucero MIRC I se observa claramente un desplazamiento esteoeste de la misma (Figura 6). Los transportes calculados para los 7 días en que fue posible hacerlo fueron de entre $1.95 \times 10^{6}$ y $7.12 \times 10^{6} \mathrm{~m}^{3} \mathrm{~s}^{-1}$ desde la zona costera hacia la zona oceánica, y de entre $0.27 \times 10^{6}$ y $2.85 \times 10^{6} \mathrm{~m}^{3} \mathrm{~s}^{-1}$ en sentido contrario (Tabla I). 


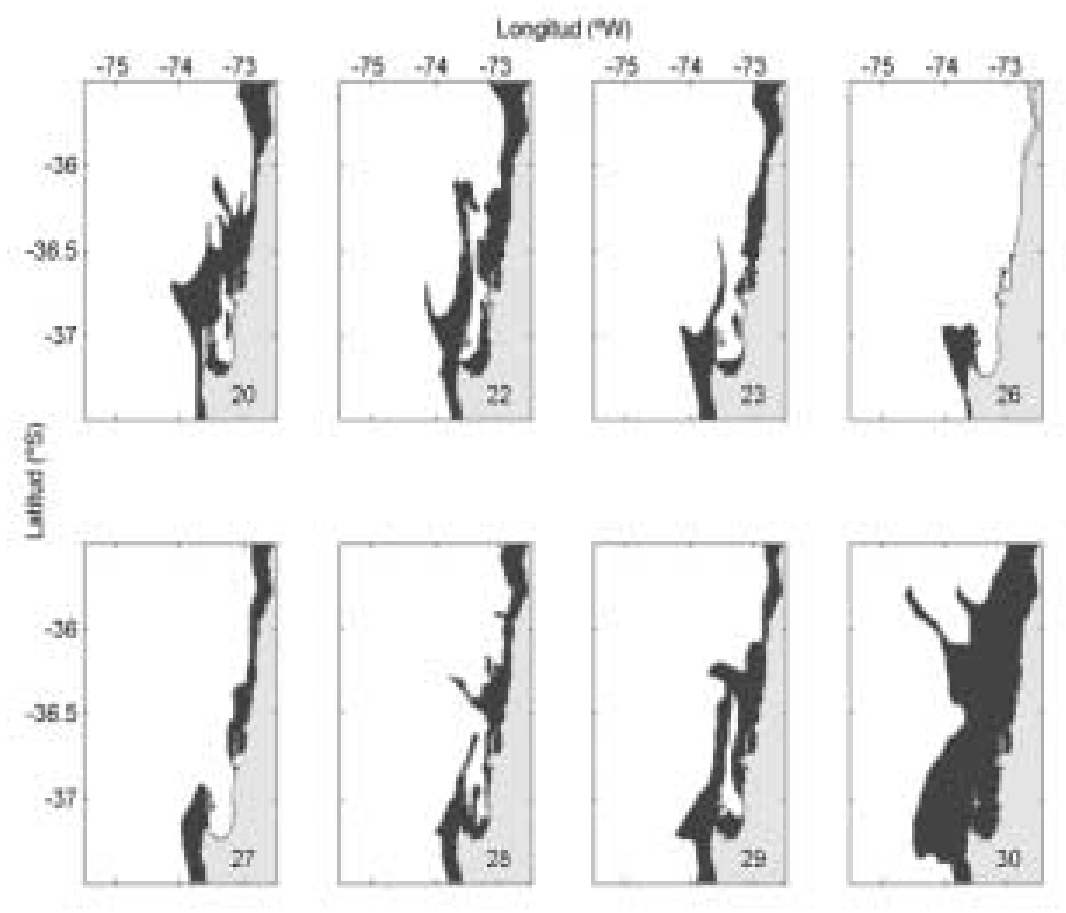

FIgURA 6. Desplazamiento de la banda de temperatura seleccionada para el MIRC I ( $10 \mathrm{a} 11^{\circ} \mathrm{C}$, gris oscuro) entre el 20 y 30 de octubre de 1998. En la esquina inferior derecha de cada figura se indica el día al que corresponden.

FIGURE 6. Displacement of the temperature band chosen for the MIRC I period $\left(10\right.$ a $11^{\circ} \mathrm{C}$, dark gray) from october 20 to october 30, 1998. In the lower right corner of each figure is shown the day to which it belongs.

\section{DISCUSION Y CONCLUSION}

\section{CRUCERO MIRC I}

El comportamiento de las estructuras de mesoescala, en cuanto a su desplazamiento en sentido este-oeste, es coherente con los períodos de surgencia y relajación indicados por los I calculados, si consideramos que el tiempo de respuesta al forzamiento de estos vientos estimado para este sistema es de 18 a 48 horas (Ahumada 1989; Sobarzo 1994). Según estos resultados, el viento estaría participando en el transporte de agua a través de estructuras de mesoescala como uno de los forzantes.

Si bien los transportes estimados para el período correspondiente al crucero MIRC I se mantuvieron dentro de un mismo rango de valores, aquellos estimados para los días 16 y 29 de Octubre fueron particularmente altos (Tabla I). La sobrestimación del flujo océano-costa para el día 16 de octubre se atribuye a la alta cobertura nubosa que presentaban las imágenes para ese día y el anterior. El día 29 de octubre, en tanto, parte del aumento en el área ocupada por las estructuras de mesoescala se debió a la expansión de un remolino ubicado frente a Punta Lavapié, no a un desplazamiento real de esa estructura, lo que causó una sobrestimación del flujo costa-océano.

Los transportes diarios cuantificados a partir de imágenes de TSM presentaron, hacia fines de octubre, cierto desfase con respecto a aquellos cuantificados con imágenes de clorofila $a$, lo que se puede interpretar como el tiempo de respuesta del fitoplancton a la disponibilidad de nutrientes dentro de los filamentos formados (Tabla I). Este 
desfase, estimado en al menos dos días para la zona de estudio (Arcos et al. 1987) y en tres días para la corriente de California (Kelly 1985; fide: Thomas \& Strub 2001), no se observó entre los días 20 y 22 de octubre. A pesar de las pocas imágenes de TSM disponibles, se pudo comprobar que los valores de transporte obtenidos a partir de éstas y aquellos obtenidos a partir de imágenes de clorofila $a$ se encuentran dentro del mismo orden de magnitud y rango. Esta comparación muestra que ambos parámetros pueden ser efectivamente utilizados como trazadores pasivos con características conservativas, y que las diferencias encontradas en este caso se deben sólo a que la banda de temperatura escogida no coincide exactamente con la banda de concentración de clorofila $a$ utilizada en los cálculos.

Con una descarga histórica promedio entre 1.250 y $1.500 \mathrm{~m}^{3} \mathrm{~s}^{-1}$ para el mes de Octubre (Quiñones \& Montes 2001), la influencia del río Bío-Bío para la época de primavera es considerada somera y poco influyente sobre la zona costera cercana a su desembocadura (Ahumada 1989; Sobarzo et al. 1993). El río Bío-Bío no estaría contribuyendo entonces a la formación de filamentos y remolinos y, por lo tanto, tampoco al transporte desde la zona costera hacia la zona oceánica a través de estas estructuras de mesoescala durante esta época del año. El río Itata, con una descarga histórica promedio menor a la del río BíoBío para el mes en cuestión (entre 500 y $750 \mathrm{~m}^{3} \mathrm{~s}^{-1}$; Quiñones \& Montes 2001), tampoco estaría participando, por ende, en el transporte costaocéano.

Las diferencias de temperatura y salinidad encontradas entre los perfiles tomados dentro y fuera de un filamento son claras hasta los $100 \mathrm{~m}$ (Figura 2A y 2B). Dado que no se cuenta con perfiles más profundos dentro de los filamentos, sólo se puede especular que estas diferencias se mantienen más allá de los $100 \mathrm{~m}$, por lo que el transporte neto a través de estas estructuras estimado en $6.22 \times 10^{4} \mathrm{~m}^{3} \mathrm{~s}^{-1}$ hacia la zona oceánica para este primer crucero, realizado en período de surgencias, se podría estar subestimando.

\section{Crucero MIRC II}

Los vientos tomados en la estación meteorológica Bellavista entre los días 3 y 17 de Julio de 1999 fueron en general débiles, con alternancia entre vientos favorables y desfavorables a la surgencia (González et al. en preparación).

Para este período las mayores concentraciones de clorofila $a$ (sobre a $2.5 \mathrm{mg} \mathrm{m}^{-3}$ ) se observaron cerca de la costa y especialmente dentro del Golfo de Arauco, Bahía de Concepción y zonas aledañas (Figura 3A).

La influencia del Bío-Bío sobre el Golfo de Arauco, con una descarga histórica promedio por sobre los $2000 \mathrm{~m}^{3} \mathrm{~s}^{-1}$ para el mes de julio (Quiñones \& Montes 2001), se produce en esta época del año a través de la formación de una pluma de baja densidad que abarca una amplia área sobre la plataforma continental, con un fuerte impacto en los primeros $15 \mathrm{~m}$ y disminuyendo la salinidad hasta los $20 \mathrm{~m}$ (Sobarzo et al. 1993). En este caso se encontró que la influencia mencionada para la salinidad alcanza los $25 \mathrm{~m}$. Bajo los $25 \mathrm{~m}$, las salinidades (34.1 a 34.5) corresponden a una mezcla de ASA y AIA (Figura 3C). El ingreso de esta agua continental, por su parte, sería capaz de producir vórtices y gradientes de densidad a los que se asocian altas concentraciones del pigmento (Serra et al. 1994), como las observadas para este período.

El efecto de eventos de viento norte en la circulación y productividad del sector del Golfo de Arauco y Punta Lavapié, donde se registraron los mayores filamentos durante nuestro estudio, se han analizado sólo entre eventos de surgencia, cuando sopla viento norte por algunos días (Djurfeldt 1989; Sobarzo et al. 2001). Cuando los vientos del sur cesan, se produce una inversión en respuesta de las aguas, que podría favorecer la productividad primaria, y la exportación de aguas hacia la zona oceánica. Algo similar pudiera estar ocurriendo con la Bahía de Concepción, para la cual también se ha postulado la exportación de aguas hacia zonas adyacentes (Ahumada 1989).

Observaciones anteriores indican que las aguas del río Bío-Bío tenderían a calentar los primeros 15 a $20 \mathrm{~m}$ de las aguas dentro del Golfo de Arauco en época de invierno (Sobarzo et al. 1993). Lo anterior no concuerda con las menores temperaturas observadas en este trabajo dentro de los filamentos (Figura 3B). En estes caso, los perfiles de temperatura muestran un efecto de los ríos en las capas más superficiales, al parecer contrarrestado por el ingreso de aguas oceánicas hacia la zona costera. Para áreas de intensa surgencia costera en el centro-norte de nuestro país se ha 
sugerido que la intrusión de aguas más oligotróficas desde la zona oceánica hacia la zona costera podría tener un efecto negativo sobre la productividad primaria (Torres 1995, Morales et al. 1996). Las menores concentraciones de clorofila $a$ encontradas durante el período correspondiente al crucero MIRC II se explicarían por una combinación de este efecto y una disminución de los vientos favorables a la surgencia.

Mientras la temperatura indica más mezcla que estratificación, atribuible a la subsidencia causada por los vientos, la salinidad indica estratificación producto de la influencia del río. Con los antecedentes disponibles en este trabajo, no es posible establecer cuál de las dos situaciones descritas, mezcla o estratificación, sería más común para el período de invierno analizado. Cerca de la desembocadura del río Itata, en tanto, se observaron altas concentraciones de clorofila $a$ en la zona costera, pero bajas en la zona oceánica adyacente, y sin la formación de ningún filamento que pudiera participar en el transporte superficial de aguas hacia la zona oceánica en ese sector.

El transporte superficial neto de agua a través del quiebre de la plataforma continental resultó también desde la zona costera hacia la zona oceánica, a pesar de que en 10 de 16 días el transporte se produjo en sentido contrario (Tabla I). Los transporte costa-afuera registrados los días 3 , 7, 9, 16 y 17 de Julio ponen en evidencia la importancia que pueden llegar a tener eventos extremos en relación a eventos que están ocurriendo la mayor parte del tiempo. Huthnance (1995) destacó la importancia de estos eventos extremos con respecto al transporte de sedimentos en otros sistemas de surgencia.

TRANSPORTE SUPERFICIAL DE AGUA ENTRE LA ZONA COSTERA Y LA ZONA OCEANICA.

La metodología utilizada en este trabajo para calcular transporte de agua a través de filamentos y remolinos supone que la clorofila $a$ se puede utilizar como un trazador pasivo con características conservativas y que este transporte se debe a un movimiento puramente advectivo de las estructuras de mesoescala definidas. A pesar de que esta suposición no es del todo correcta, se puede considerar válida para las escalas espacio-tem- porales abarcadas en este trabajo.

Los valores de transporte calculados aquí a partir de imágenes satelitales de clorofila $a$ concuerdan con los transportes de entre $1 \mathrm{a} 4 \times 10^{6} \mathrm{~m}^{3} \mathrm{~s}^{-1}$ estimados por otros autores (principalmente a través de mediciones directas) para filamentos individuales identificados en otras regiones del mundo (Brink1987; Jones et al. 1991; Ramp et. al 1991; Huthnance 1995; Kosro and Huyer 1986).

Para los dos períodos analizados (15 días en octubre de 1998 y 15 días en Julio de 1999) se encontró un transporte superficial neto de agua desde la zona costera hacia la zona oceánica a través de las estructuras identificadas. Si bien el origen de los filamentos y remolinos observados no está del todo claro, en ambos períodos estas estructuras presentaron características claramente distintas a las aguas circundantes, y a través de ellas se estaría exportando un considerable volumen de agua con altas concentraciones de nutrientes y clorofila $a$, de gran importancia biológica, hacia la zona oceánica. Este transporte sería particularmente importante durante el período de primavera, ya que en este caso se estaría subestimando al no conocerse la estructura térmica y de salinidad de los filamentos más allá de los $100 \mathrm{~m}$ de profundidad.

Los filamentos identificados durante el primer período de estudio (primavera de 1998) parecieran estar asociados a eventos de surgencia, presentando características de este tipo en sus aguas. Durante el período de invierno considerado (segundo crucero), en tanto, estas estructuras parecieran estar siendo influenciadas tanto por agua de ríos como por aguas oceánicas, hundiéndose en la costa. De ser efectivo el origen de los filamentos hipotetizado en este trabajo para cada período, cualquier variabilidad o anomalía en los eventos de surgencia afectaría el transporte costa-afuera estimado para el período de primavera, así como cualquier variabilidad o anomalía en las descargas de los ríos y subsidencia de agua oceánica en la costa afectaría el transporte durante el período de invierno.

\section{AGRADECIMIENTOS}

Esta investigación fue financiada por el proyecto Fondecyt 1000373. Carolina Grob fue además financiada por una beca de investigación otorgada 
por el Departamento de Física de la Atmósfera y el Océano (DEFAO) de la Universidad de Concepción. Se agradece al Centro COPAS (Programa FONDAP, CONICYT, Chile) por la data oceanográfica de los cruceros MIRC I y MIRC II, al DEFAO por los datos de viento de Punta Lavapié y Bellavista. El Instituto de Investigación Pesquera Octava Región S.A. y Jaime Letelier facilitaron las imágenes satelitales de TSM. Las imágenes SeaWIFS fueron provistas por el Programa de Oceanografía Física y Clima (Universidad de Concepción). Leonardo Castro facilitó el programa OPTIMAS 6.1. Deseamos expresar nuestro sincero reconocimiento a Gabriel Yuras por su contribución al procesamiento de las imágenes de SeaWIFS. Finalmente quisiéramos expresar nuestro agradecimiento a Marcus Sobarzo, Arnoldo ValleLevinson, Wolfgang Schneider, Oscar Pizarro y Carlos Moffat por sus comentarios sobre una versión previa de este manuscrito.

\section{BIBLIOGRAFIA}

Ahumada, R. 1989. Producción y destino de la biomasa fitoplanctónica en un sistema de bahías en Chile central: una hipótesis. Biol. Pesq. 18: 53-66.

Arcos, D.F. 1987. Seasonal and short time scale variability in copepod abundance and species composition in an upwelling area off Concepción Coast, Chile. Ph. D. Dissertation. State University of New York, Stony Brook. 203pp.

Arcos, D. \& N. Navarro. 1986. Análisis de un índice de surgencia para la zona de Talcahuano, Chile (Lat.37º ). Invest. Pesq. (Chile), 33: 91-98.

Arcos, D.F., S.P. Nuñez, L. Castro \& N. Navarro. 1987. Variabilidad vertical de clorofila $a$ en un área de surgencia frente a Chile Central. Invest. Pesq. (Chile) 34: 47-55.

BAKUN, A. 1975. Daily and Weekly upwelling indices, west coast of North America, 1967-73. U.S. Dep. Commer.; NOAA Tech. Rep. NMFS-SSRS-693, 9pp.

Breaker, L.C., V.M. Krasnopolsky, D.B. Rao \& X.H. YAN. 1994. The feasibility of estimating ocean surface currents on an operational basis using satellite feature tracking methods. Bulletin of the American Meteorological Society, 75, 20852095.

BRINK, K.H. 1987. Coastal Ocean Physical Processes. U.S. National Report to International Union of Geodesy and Geophysics, 1983-1986. Reviews of Geophysics 25(2): 204-216.

CÁCERES, M. 1990. Variabilidad espacial y temporal de la Temperatura Superficial del Mar (TSM) frente a Concepción, Chile central, usando percepción remota. Tesis de Magíster en Ciencias Mención Oceanografía. Concepción. Universidad de Concepción. 90pp.

CÁCERES, M. 1992. Vórtices y filamentos observados en imágenes de satélite frente al área de surgencia de Talcahuano, Chile central $\left(33-38.5^{\circ} \mathrm{S}\right)$. Invest. Pesq. (Chile), 37: 55-66.

Cáceres, M. \& D. Arcos. 1991. Variabilidad en la estructura espacio-temporal de un área de surgencia frente a la costa de Concepción, Chile. Invest. Pesq. (Chile), 36: 27-38.

Daneri, G., V. Dellarossa, R. Quiñones, B. Jacob, P. Montero \& O. Ulloa. 2000. Primary production and community respiration in the Humboldt Current System off Chile and associated oceanic areas. Mar. Ecol. Prog. Ser., Vol. 197: 41-49.

DJuRFELDT, L. 1989. Circulation and mixing in a coastal upwelling embayment; Golf of Arauco, Chile. Continental Shelf Research 9, 1003-1016.

Hill, A.E., B.M. Hickey, F.A. Shillington, P.T. Strub, K.H. BRINK, E.D. BARTON \& A.C. Thomas. 1998. Eastern Ocean Boundaries Coastal Segment (E). The Sea. Vol. 11: 30-67. John Wiley \& Sons, Inc.

Huthnance, J.M. 1995. Circulation, exchange and water masses at the ocean margin: the role of physical processes at the shelf edge. Prog. Oceanogr. Vol. 35: 353-431.

Jones, B.H., C.N.K. Mooers, M.M. RieneCKer, T. Stanton \& L. Washburn. 1991. Chemical and biological structure and transport of a cool filament associated with a Jet-Eddy System off Northern California in July 1986 (OPTIMA21). J. Geophys. Res. 96 (C12): 22,207-22,225.

Kosro P.M. \& A. Huyer. 1986. CTD and velocity surveys of seaward jets off northern California, July 1981 and 1982. J. Geophys. Res. 91: 7,680-7,690.

Kosro P.M., A. Huyer, S.R. Ramp, R.L. Smith, F.P. Chávez, T.J. Cowles, M.R. Авbott, P.T. Strub, R.T. Barber, P. Jessen \& L.F. Small. 1991. The Structure of the Transition Zone Between Coastal Waters and the Open Ocean off Northern California, Winter and Spring 1987. J. Geophys. Res. 96 (C8): 14,707-14,730.

Morales, C.E., J.L. Blanco, M. Braun, H. Reyes \& N. SiLva. 1996. Chlorophyll-a distribution and associated oceanographic conditions in the upwelling region off northern Chile during the winter and spring 1993. Deep-Sea Res. 43: 267289.

Pickard, G.L. \& W.J. Emery. 2000. Descriptive Physical Oceanography: an Introduction. Fifth (SI) Enlarged Edition. Butterworth-Heinemann Ltd., Oxford. 320pp.

Pond, S. \& G.L. PickARD. 1997. Introductory Dynamical Oceanography. Second Edition. ButterworthHeinemann Ltd., Oxford. 329pp.

QuiÑones, R. \& R. Montes. 2001. Relationship between freshwater input to the coastal zone and the historical landings of the benthic/demersal fish 
Eleginops maclovinus in central-south Chile. Fish. Oceanogr. 10 (4): 311-328.

Ramp, S.R., P.F. Jessen, K.H. Brink, P.P. NiILER, F.L. DAGgETT \& J.S. Best. 1991. The physical structure of cold filaments near point Arena, California, During June 1987. J. Geophys. Res. 96 (C8): $14,859-14,883$.

SAAVEDRA, N. 1980. La presión y la dirección del viento en Concepción. Tralka (Chile) 1: 153-162.

Sernapesca. 2000. Anuario Estadístico de Pesca. 195pp.

Serra, R., H. Arancibia, D. Arcos, M.A. Barbieri, J.L. Blanco, J. Córdova, H. Muñoz, S. Núñez, J. Osses, R. Quiñones \& H. Roвotham. 1994. Evaluación directa del stock de jurel en la zona centro-sur. Informe IFOP. 230pp.

Shillington, F.A., W.T. Peterson, L. Hutchings, T.A. Probyn, H.N. Waldron \& J.J. Agenbag. 1990. A cool upwelling filament off Namibia, Southwest Africa: preliminary measurements of physical and biological features. Deep-Sea Res. 37: 17531772.

Smyth, T.J., P.I. Miller, S.B. Groom, S.J. Lavender. 2001. Remote sensing of sea surface temperature and chlorophyll during Lagrangian experiments at the Iberian margin. Prog. Oceanogr. Vol. 51:269-281.

Sobarzo, M. 1994. Oceanografía Física entre Punta Nugurne (35 $57^{\circ} \mathrm{S}$; $\left.72^{\circ} 47^{\prime} \mathrm{W}\right)$ y Punta Manuel (38³0'S; $\left.73^{\circ} 31^{\prime} \mathrm{W}\right)$, Chile: una revisión histórica (1936-1990). Gayana Oceanol. 2(1): 517.

Sobarzo, M. 1999. Surgencia costera sobre una plataforma continental limitada por cañones submarinos, Concepción, Chile central ( $36^{\circ} 40^{\prime} \mathrm{S}$; $\left.73^{\circ} 15^{\prime} \mathrm{W}\right)$. Tesis de Doctorado, Universidad de
Concepción. 236pp

Sobarzo, M., E. Sansone, A. Demaio, D. Arcos, M. Salamanca \& J. HenríQuez. 1993. Variabilidad espacio-temporal de la estructura hidrográfica de las aguas del Golfo de Arauco. Scientific Report Series, Vol. 4, EULA Environmental Sciences Center, University of Concepción, Chile, unpublished.

Sobarzo, M. \& D. Figueroa. 2001. The physical structure of a cold filament in a Chilean upwelling zone (Península de Mejillones, Chile, $23^{\circ} \mathrm{S}$ ). Deep-Sea Res. I 48: 2699-2726.

Sobarzo, M., D. Figueroa \& L. Duurfeldt. 2001. Upwelling of subsurface water into the rim of the Bío-Bío submarine canyon as a response to surface winds. Cont. Shelf Res. 21: 279-299.

Strub, P.T., J. Mesías, V. Montecino, J. Rutlland \& S. SALINAS. 1998. Coastal Ocean Circulation off Western South America, in The Sea, Vol. 10, part B, edited by A.R. Robinson and K.H. Brink, pp. 273-314. John Wiley, New York.

Thомаs, A. 1999. Seasonal distributions of satellite-measured phytoplankton pigment concentration along the Chilean coast. J. Geophys. Res. 104 (C11): 25,877-25,890.

Thomas, A. \& T. Strub. 2001. Cross-shelf phytoplankton pigment variability in the California Current. Cont. Shelf Res. 21: 1157-1190.

Torres, R. 1995. Condiciones oceanográficas de surgencia y baja concentración de clorofila frente a Coquimbo-Chile (Lat 30º ) durante 1992-1994. MSc Thesis, Department of Oceano-graphy, University of Concepción, Concepción, Chile, $123 \mathrm{p}$.

Fecha de recepción: 11/03/02

Fecha de aceptación: 20/10/02 